\title{
History: Tribute to Ralph Lazarra, MD (August 14, 1934-January 16, 2018)
}

\author{
Benjamin J. Scherlag ${ }^{1} \cdot$ Franklin G. M. Theelen ${ }^{1}$
}

Published online: 10 April 2018

(C) Springer Science+Business Media, LLC, part of Springer Nature 2018

Founding Associate Editor, Journal of Interventional Cardiac Electrophysiology

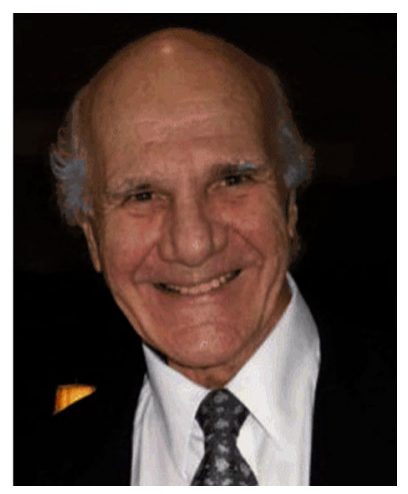

Dr. Lazzara served an internship at the Ochsner Clinic and Ochsner Foundation Hospital, followed by a residency and fellowship in internal medicine and cardiology at Tulane University and Charity Hospital, then a year of special fellowship in electrophysiology at Columbia University College of Physicians and Surgeons in the Department of Pharmacology. He returned to Ochsner where he was a staff cardiologist and director of cardiovascular research from 1965 to 1967 . He served in the US Army from 1967 to 1970, achieving the rank of Lieutenant Colonel. He then moved to Mt. Sinai Medical Center and the University of Miami from 1970 to 1972 and the Veterans Administration Medical Center and University of Miami from 1972 to 1978, achieving the rank of Professor of Medicine. He was the director of the coronary care unit, then chief of cardiology at the Veterans Administration Medical

Benjamin J. Scherlag

Benjamin-Scherlag@ouhsc.edu

1 Health Sciences Center, University of Oklahoma, Oklahoma City, Oklahoma, USA
Center from 1974 to 1978 . He moved to Oklahoma as a Professor of Medicine and as chief of the cardiovascular section at the University of Oklahoma Health Sciences Center where he served from 1978 to 1998, stepping down as chief to become director of the Heart Rhythm Institute of the University of Oklahoma Health Sciences Center. He was fully active with clinical care and teaching until his infirmities restricted some of his many activities.

He was elected to the American Society for Clinical Investigation, the Association of American Physicians, and the Association of University Cardiologists.

He received the Distinguished Scientist Award from the North American Society of Pacing and Electro-physiology, now the Heart Rhythm Society, and was president of the Society in 1995. His awards included the positions of OU Regents Professor of Medicine, Natalie O. Warren Professor of Medicine, George Lynn Cross Research Professor, the position of Honorary Professor of Medical Ethics at Xinjiang Medical University in Xinjiang, PR China, and the Outstanding Alumnus Award 2010 from Tulane Medical School.

Ralph was both a pioneer and world leader in electrophysiology and cardiac ablation and an outstanding mentor and teacher. He was responsible for recruiting basic and clinical scientists who have revolutionized the field of cardiac electrophysiology. Under his leadership, ablation techniques were developed to treat and cure patients with WPW, AVNRT, and ventricular tachyarrhythmias among others.

Dr. Lazzara, as a basic researcher, was a skilled laboratory scientist whose virtuosity with the microelectrode technique provided evidence that refuted a long standing concept developed at the end of the 19th century. It was believed that the His bundle, under normal conditions, consisted of segregated tracts whereby some conducting fibers were destined to innervate the left or right bundle branch systems, i.e., functional longitudinal dissociation. The definitive study to establish the syncitial structure and function of the His bundle cells in the normal heart was performed by Lazzara and associates (see Figure 1, below). 


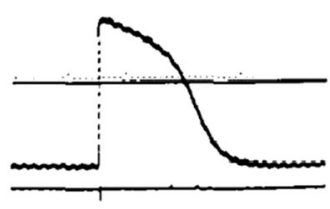

A
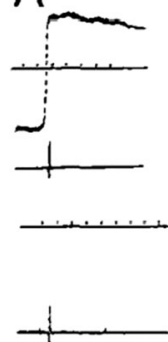

Fig. 1 Intracellular stimulation in the His bundle (HB). An action potential recorded from the His bundle of the rabbit is shown at the top left along with the bipolar electrogram recorded from the right bundle branch. At the top right, there is a schematic representation of the His bundle with recording and stimulating sites depicted with crosses. The top two traces of A-C show the upstrokes of action potentials recorded from these sites and the right bundle branch electrogram, when the atrium was stimulated. The bottom trace of A-C shows the right bundle branch electrogram when the respective cells in the His bundle were stimulated intracellularly. The interval from action potential upstroke to the electrogram from the right bundle branch is the same as the interval from the stimulus artifact to the electrogram in each case, and the electrograms are identical in configuration. The vertical bar represents $100 \mathrm{mv}$ for the intracellular recording (Circ Res. 1973;32(4):509-15).

In a novel in vitro preparation of the His bundle and the bundle branch system [1], Ralph was able to show the His bundle consisted of cells which were highly interconnected and acted as a syncytium. By using a microelectrode to deliver current into each of a number of His bundle cells, he demonstrated that the propagated wave front activate both left and right bundle systems in the same way that extrinsic excitation of the bundle induced. Delivering the same current level at the surface did not activate the His bundle thereby failed to activate the bundle branches. Further studies showed that pathologic conditions, e.g., ischemia, induced functional blocks in the His bundle which the led to bundle branch blocks both in the in vitro preparation as well as in patients with bundle branch block pattern on their ECGs. Moreover, His bundle pacing normalized the QRS. With the advent of permanent His bundle pacing, some 27 years later, a new and more effective method for treating heart failure in patients is emerging to replace biventricular pacing for cardiac resynchronization therapy.

Other important contributions that were made by Dr. Lazarra include studies of the basic arrhythmias due to the long QT syndrome [2-4].

\section{References}

1. Lazzara R, Yeh BK, Samet P. Functional transverse interconnections within the His bundle and the bundle branches. Circ Res. 1973;32(4): $509-15$.

2. Schechter E, Freeman CC, Lazzara R. Afterdepolarizations as a mechanism for the long QT syndrome: electrophysiologic studies of a case. J Am Coll Cardiol. 1984;3(6):1556-61.

3. Brachmann J, Scherlag BJ, Rosenshtraukh LV, Lazzara R. Bradycardia-dependent triggered activity: relevance to druginduced multiform ventricular tachycardia. Circulation. 1983;68(4): $846-56$.

4. Lazzara R. Mechanisms and management of congenital and acquired long QT syndromes. Arch Mal Coeur Vaiss. 1996 Feb;89 spec no 1: 51-5. Review. 